Check for updates

Cite this: Nanoscale Adv., 2019, 1, 3761

\title{
Three-step-in-one synthesis of supercapacitor MWCNT superparamagnetic magnetite composite material under flow' $\uparrow$
}

\author{
Thaar M. D. Alharbi, ${ }^{\text {ab }}$ Ahmed H. M. Al-Antaki, (D) ${ }^{a}$ Mahmoud Moussa, \\ Wayne D. Hutchison (D) and Colin L. Raston (D)*a
}

Composites of multi-walled carbon nanotubes (MWCNTs) and superparamagnetic magnetite nanoparticles, $\mathrm{Fe}_{3} \mathrm{O}_{4} \mathrm{QMWCNT}$, were synthesized in DMF in a vortex fluidic device (VFD). This involved in situ generation of the iron oxide nanoparticles by laser ablation of bulk iron metal at $1064 \mathrm{~nm}$ using a pulsed laser, over the dynamic thin film in the microfluidic platform. The overall processing is a threestep in one operation: (i) slicing MWCNTs, (ii) generating the superparamagnetic nanoparticles and (iii) decorating them on the surface of the MWCNTs. The $\mathrm{Fe}_{3} \mathrm{O}_{4} @$ aMWCNT composites were characterized by transmission electron microscopy, scanning transmission electron microscope, TG analysis, $\mathrm{X}$-ray diffraction and $\mathrm{X}$-ray photoelectron spectroscopy. They were used as an active electrode for supercapacitor measurements, establishing high gravimetric and areal capacitances of $834 \mathrm{~F} \mathrm{~g}^{-1}$ and $1317.7 \mathrm{mF} \mathrm{cm}^{-2}$ at a scan rate of $10 \mathrm{mV} \mathrm{s}^{-1}$, respectively, which are higher values than those reported using similar materials. In addition, the designer material has a significantly higher specific energy of $115.84 \mathrm{~W} \mathrm{~h} \mathrm{~kg}^{-1}$ at a specific power of $2085 \mathrm{~W} \mathrm{~kg}^{-1}$, thereby showing promise for the material in nextgeneration energy storage devices.

Received 2nd June 2019

Accepted 16th August 2019

DOI: 10.1039/c9na00346k

rsc.li/nanoscale-advances establishing that the electrochemical performance is enhanced. ${ }^{15,16}$

Decorating carbon nanotubes with inorganic nanoparticles has received considerable attention both in fundamental research and the industrial arena. ${ }^{17}$ This relates to the unique physical and chemical properties of the composite materials. Indeed, MWCNTs decorated with iron oxide particles in general are promising composite materials for a variety of applications such as hydrogen storage, ${ }^{18}$ imaging and therapy, ${ }^{17,19}$ gas sensors, ${ }^{20}$ catalysis, ${ }^{17,21}$ CNT-based magnetic materials, ${ }^{22}$ CNT field emitters, ${ }^{17,23}$ and CNT-based electronic devices. ${ }^{17,24,25}$ Various routes have been developed in gaining access to such material, including solvothermal, ${ }^{26}$ hydrothermal, ${ }^{27}$ microwave, ${ }^{28}$ laser ablation ${ }^{29}$ and ultra-sonication processing ${ }^{30}$ hightemperature decomposition, ${ }^{31}$ laser pyrolysis ${ }^{32}$ and chemical vapour deposition. ${ }^{33}$ Freedman $e t ~ a l .{ }^{34}$ and Singhal et al. ${ }^{35}$ have demonstrated that a magnetic carbon nanotube pipette is effective for transferring liquid into and within a single cell. In addition, Šljukić et al. ${ }^{36}$ have shown that the electrochemical activity of carbon nanotubes for the reduction of $\mathrm{H}_{2} \mathrm{O}_{2}$ can arise from iron oxide nanoparticles decorated on CNT. Also noteworthy is that carbon nanotubes decorated with iron(III) oxide $\left(\mathrm{Fe}_{2} \mathrm{O}_{3}\right)$ nanoparticle embedded in a co-polymer (derived from pyrrole and 3-carboxylated pyrrole) are highly sensitive for detecting $\mathrm{H}_{2} \mathrm{~S}$, as reported by Kim et al. ${ }^{37}$ Thus CNT-iron oxide nanoparticle composites have a diverse range of applications, and accordingly we sort to develop a robust synthesis of such 
material, ideally under continuous flow, as a potentially scalable process.

Previously we reported on the synthesis of superparamagnetic magnetite $\left(\mathrm{Fe}_{3} \mathrm{O}_{4}\right)$ nanoparticles, spheroidal and hexagonal shaped, with an average size of $c a .15 \mathrm{~nm}$, using a vortex fluidic device (VFD). ${ }^{38}$ Here the magnetite nanoparticles are generated by pulsed laser ablation of an iron rod (high purity, >99.998\%) at $1064 \mathrm{~nm}$, with the rod positioned over the dynamic thin film in the VFD, Fig. 1a, under at atmosphere of air. This is a single-step continuous flow process, and the operation of the VFD is effectively using it as a metal vapour synthesiser. In an analogous way, the VFD has been used for decorating hexagonal boron nitride (h-BN) with similar sized magnetite nano-particles, now as a one step process for making composite materials. ${ }^{39}$ Inspired by the aforementioned findings, we were motivated to translate this knowhow into developing a facile continuous flow VFD mediated process for decorating MWCNTs with magnetite nanoparticles, $\mathrm{Fe}_{3} \mathrm{O}_{4}$ @MWCNT, in using the shear stress in the VFD to disentangle the MWCNTs which while irradiated with a the pulsed laser are sliced into more processible lengths. ${ }^{40}$ Thus it is a novel three in one continuous flow process, and we establish that the resulting composite material, $\mathrm{Fe}_{3} \mathrm{O}_{4} @ M W C N T s$, is an active electrode for supercapacitance, achieving a high gravimetric $\left(834 \mathrm{~F} \mathrm{~g}^{-1}\right)$ and areal (1317.7 $\mathrm{mF} \mathrm{cm}^{-2}$ ) capacitances, which are enhanced compared with those previously reported for iron oxide/carbon anodes. ${ }^{41}$ We note that the decoration of SWCNTs with magnetite nanoparticles has been established using the related spinning disc processor (SDP), also under continuous flow, but the process requires the use of harsh chemicals and pretreatment (oxidation and binding of $\mathrm{Fe}^{2+}$ and $\mathrm{Fe}^{3+}$ ) of the SWCNTs ${ }^{42}$ and thus where the integrity of the carbon nanotubes is lost.

The VFD is a versatile microfluidic platform with a diversity of applications, including in processing carbon nanomaterials, as in slicing of SWCNTs, especially in controlling their length, ${ }^{\mathbf{4 3}}$ exfoliation of graphite and boron nitride, ${ }^{\mathbf{4}}$ transforming graphene oxide sheets into scrolls, ${ }^{45}$ decorating carbon nanoonions with $\mathrm{Pt}^{46}$ and $\mathrm{Pd}^{47}$ nanoparticles, the synthesis of carbon dots, ${ }^{48}$ and the fabrication of $\mathrm{C}_{60}$ tubules using water as an 'anti-solvent'. ${ }^{49}$ Other applications of the VFD include controlling chemical reactivity and selectivity, ${ }^{50}$ protein folding, ${ }^{51}$ enhancing enzymatic reactions ${ }^{52}$ and protein immobilization. ${ }^{53}$ The dynamic thin film in a VFD has Stewartson/ Ekman layers and Faraday pressure waves, with the liquid moving up the rapidly rotating tube under gravitational force and exiting at the top. ${ }^{54}$ The continuous flow mode of operation of the VFD has the attractive feature of addressing scalability of a process at the inception of the research. Here jet feeds deliver reagents into an inclined rapidly rotating tube, typically a $20 \mathrm{~mm}$ O.D. glass or quartz tube. ${ }^{55}$

\section{Experimental section}

\subsection{Materials}

MWCNTs used in the present work have an average outside diameter (O.D.) $\times$ inside diameter (I.D.) $\times$ length equivalent dimensions $10 \mathrm{~nm} \pm 1 \mathrm{~nm} \times 4.5 \mathrm{~nm} \pm 0.5 \mathrm{~nm}$, and 3 to $6 \mu \mathrm{m}$ respectively. They were purchased from Sigma-Aldrich, as chemical vapour deposition prepared material with an as received purity $\geq 98 \%$, and were used as received. $N, N$-Dimethylformamide (DMF) was purchased from Sigma-Aldrich and used as received. High purity Fe $(>99.998 \%) 8361 \mathrm{~h}$ iron rod, $5 \mathrm{~mm}$ in diameter (Koch-Light Laboratories) was used as the laser target and source of metal.

\subsection{Fabrication of $\mathrm{Fe}_{3} \mathrm{O}_{4} @ M W C N T$}

The preparation of $\mathrm{Fe}_{3} \mathrm{O}_{4} @ M W C N T$ nanocomposites is shown in Fig. 1a. MWCNTs were dispersed in $\mathrm{N}, \mathrm{N}$-dimethylformamide (DMF) at a concentration of $0.08 \mathrm{mg} \mathrm{mL}^{-1}$ and the mixture ultrasonicated for 15 minutes prior to VFD processing. The experimental setup mainly followed the previously published work for the VFD mediated slicing of CNTs and the synthesis of superparamagnetic nanoparticles, ${ }^{\mathbf{3 8 , 4 0 , 4 3}}$ in merging two different applications of the VFD. The experiments were carried out using the continuous flow mode of operation of the device at a flow rate of $0.45 \mathrm{~mL} \mathrm{~min}^{-1}$. Stainless steel jet feed was used to deliver MWCNTs dispersed in DMF solution to the bottom of
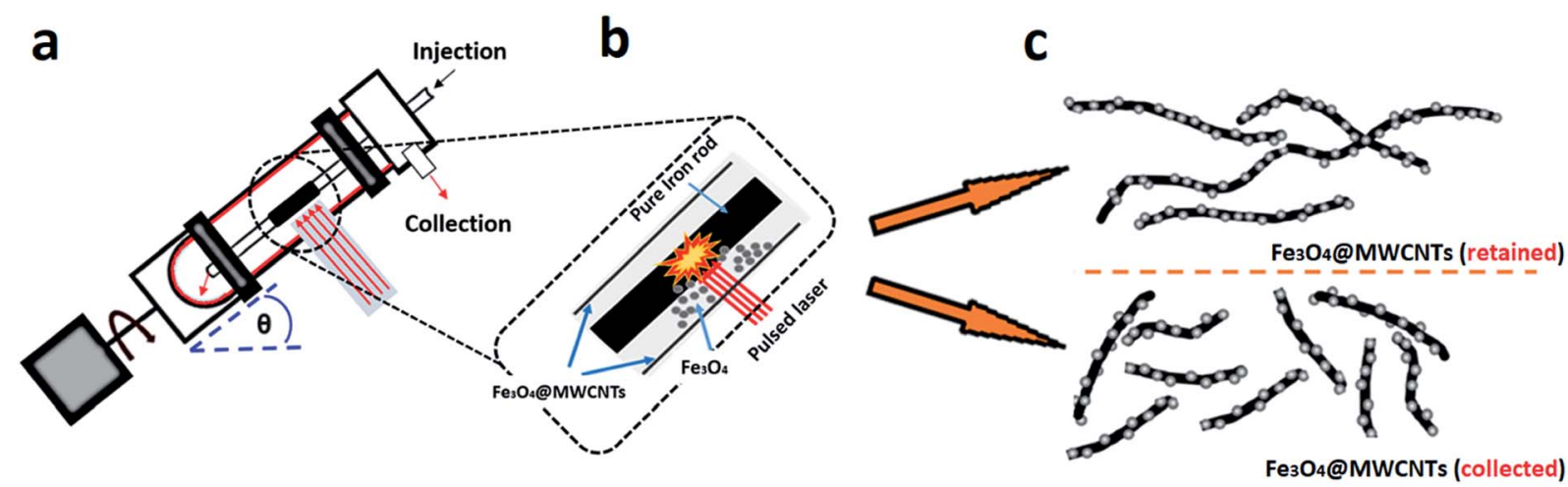

Fig. 1 Schematic illustration of the experimental procedure for the preparation for $\mathrm{Fe}_{3} \mathrm{O}_{4}$ @MWCNT. (a) The vortex fluidic device (VFD) and laser $\mathrm{Nd}$ :YAG processing at $1064 \mathrm{~nm}$. (b) Zoomed in schematic for generating $\mathrm{Fe}_{3} \mathrm{O}_{4} \mathrm{NPs}$ under laser irradiation of an iron rod (power at $250 \mathrm{~mJ}$ ). (c) $\mathrm{Fe}_{3} \mathrm{O}_{4} \mathrm{QMWCNT}$ exiting the tube under continuous flow (collected) and retained in the tube. 
the rapidly rotating quartz tube (O.D. $20 \mathrm{~mm}$, I.D. $17.5 \mathrm{~mm}$ ). The tilt angle $(\theta)$ of the device was $45^{\circ}$, which is the optimal angle for a number of VFD processes, ${ }^{43-45,48}$ relative to the horizontal position. For fabricating $\mathrm{Fe}_{3} \mathrm{O}_{4} @ M W C N T s$, the iron rod was immobilized on a stainless steel jet feed and irradiated in the VFD tube at a wavelength of $1064 \mathrm{~nm}$ using a Q-switched Nd:YAG laser (Spectra Physics GCR170) operating at a pulse repetition rate of $10 \mathrm{~Hz}$. The power of the laser was optimized first by conducting the experiment under continuous flow conditions at different laser powers, $250 \mathrm{~mJ}, 400 \mathrm{~mJ}$ and $600 \mathrm{~mJ}$, as shown in Fig. S5 (ESI $\dagger$ ). For high laser powers, 400 and 600 $\mathrm{mJ}$, the MWCNTs were unzipped and fragmented, whereas at the optimum laser power $(250 \mathrm{~mJ}), \mathrm{Fe}_{3} \mathrm{O}_{4}$ nanoparticles were generated and decorated on the surface of MWCNTs. Initially the MWCNTs were dispersed in DMF at a concentration of $0.08 \mathrm{mg} \mathrm{mL}^{-1}$ and were injected into the base of the quartz tube through a jet feed using a $50 \mathrm{~mL}$ glass syringe, at a flow rate of $0.45 \mathrm{~mL} \mathrm{~min}^{-1}$ while the iron rod was irradiated with the pulsed laser. After the $50 \mathrm{~mL}$ of the solutions was delivered, the experiment was stopped, affording two products, one exiting the VFD tube during the processing (collected), which accounted for $42 \%$ of the isolated material, with $58 \%$ of the material generated remaining in the tube (retained). Both products contained MWCNTs decorated with $\mathrm{Fe}_{3} \mathrm{O}_{4}$ nanoparticles in a high yield, based on the amount of MWCNTs consumed and the overall weight of the combined product taking into account the ratio of magnetite to MWCNTs.

\subsection{Electrochemistry}

A specific amount of active material $(10 \mathrm{mg})$ was sonicated for $1 \mathrm{~h}$ in $20 \mathrm{~mL}$ of ethanol. Next, the resulting suspension was vacuum filtered through a PTFE membrane to make a freestanding film. The composite film was cut into electrodes of footprint area of $1 \mathrm{~cm}^{2}$, and platinum foils were used as current collectors and $1 \mathrm{M} \mathrm{Na}_{2} \mathrm{SO}_{4}$ as electrolyte. Cyclic voltammetry (CV) and galvanostatic charge/discharge (CD) were carried out by a two-electrode configuration using a CHI 660E electrochemical workstation. All measurements were performed at room temperature. The gravimetric capacitance and areal capacitance were calculated from CV curves.

\subsection{Characterization}

X-ray powder diffraction (XRD) data were collected using a Bruker Advanced D8 diffractometer (capillary stage) using Co$\mathrm{K} \alpha\left(\lambda=1.7889 \AA\right.$ $\left., 35 \mathrm{~kW} / 28 \mathrm{~mA}, 2 \theta=10-90^{\circ}\right)$. Thermogravimetric analysis (TGA) was recorded on a Perkin Elmer STA8000 operating at a heating rate of $10{ }^{\circ} \mathrm{C} \mathrm{min}{ }^{-1}$ under an air gas flow. Atomic force microscopy (AFM) using a Nanoscope 8.10 in tapping mode and transmission electron microscopy (TEM) was conducted on a TECNAI 20 microscope operated at 120 and 200 $\mathrm{kV}$. STEM investigation and compositional mapping were conducted using an aberration-corrected FEI Titan Themis TEM operating at $200 \mathrm{kV}$ equipped with an energy dispersive X-ray spectroscopy (EDX) detector. Magnetization measurements used a Quantum Design PPMS with ACMS option at room temperature $(295 \mathrm{~K})$ in applied magnetic fields up to $2.50 \mathrm{~T}$.

\section{Results and discussion}

\subsection{Fabrication of $\mathrm{Fe}_{3} \mathrm{O}_{4} @ M W C N T$}

We have developed a high yielding method for preparing a composite material based on MWCNTs decorated with superparamagnetic magnetite $\left(\mathrm{Fe}_{3} \mathrm{O}_{4}\right)$ nanoparticles, $\mathrm{Fe}_{3} \mathrm{O}_{4}$ @MWCNT, as a three in one process - slicing, laser ablation and growth of nanoparticles, and decoration. The solvent of choice was DMF, with the processing devoid of other reagents, and the processing is therefore limiting the generation of a waste stream for any downstream applications. Salient features for preparing $\mathrm{Fe}_{3} \mathrm{O}_{4} @ M W C N T$ are schematically illustrated in Fig. 1. The $\mathrm{Fe}_{3} \mathrm{O}_{4}$ nanoparticles (NPs) are generated in situ in the VFD by irradiating a high purity ( $>99.998 \%)$ iron rod $(5 \mathrm{~mm}$ diameter) with a pulsed laser (Q-switched Nd:YAG) operating at $1064 \mathrm{~nm}$ wavelength, Fig. 1b. MWCNTs dispersed in DMF were delivered to the bottom of the rapidly rotating quartz VFD tube through a jet feed with an iron rod attached. As the liquid passes through the laser beam the MWCNTs are sliced into shorter tubes and simultaneously decorated with $\mathrm{Fe}_{3} \mathrm{O}_{4}$ NPs, Fig. 1c. The length distribution of $\mathrm{Fe}_{3} \mathrm{O}_{4} @ M W C N T$ exiting the tube is centred at $500 \mathrm{~nm}$ (inset Fig. 3a). MWCNTs which were retained in the VFD during the processing were similarly decorated with $\mathrm{Fe}_{3} \mathrm{O}_{4}$ NPs, Fig. 1c, but they are significantly longer at ca. $2 \mu \mathrm{m}$. The reason for the longer lengths of MWCNTs in the composite material being retained in the tube presumably relates to the build-up, on both sides of the laser beam, of magnetite being faster than untangling and slicing of the MWCNTs. Such build up is likely to result in magnetite particles bridging different tube which are then locked into place, with the shear stress in the fluid dynamics unable to separate them. MWCNTs sliced prior to a substantial build-up of magnetite particles on their surface, can then be decorated and move under the fluid flow. See below for further discussion on the size of the magnetite NPs and associated mass differences, and potential effect on the processing.

\subsection{Characterisation}

The nature of the $\mathrm{Fe}_{3} \mathrm{O}_{4} @ M W C N T$ nanocomposite was investigated using AFM, TEM, HRTEM and STEM. Fig. 2a and d show AFM and low magnification TEM images for the material retained in the tube during processing revealing bundles of strands mixed with a high density of $\mathrm{Fe}_{3} \mathrm{O}_{4}$ nanoparticles, seen as black areas. These modified MWCNTs appear unaltered in length relative to the as received material. Fig. $2 b$ and $c$ show TEM and HRTEM images of the same material, revealing MWCNTs decorated with $\mathrm{Fe}_{3} \mathrm{O}_{4}$ NPs. Corresponding images for $\mathrm{Fe}_{3} \mathrm{O}_{4} @ M W C N T$ flowing out of the tube (collected) are shown in Fig. 3a and d, clearly establishing that the MWCNTs have been sliced down to $500 \mathrm{~nm}$ in length (inset Fig. 3a) as well as being decorated with $\mathrm{Fe}_{3} \mathrm{O}_{4}$ nanoparticles. Fig. $3 \mathrm{~b}$ and $\mathrm{c}$ show TEM and HRTEM images of the collected $\mathrm{Fe}_{3} \mathrm{O}_{4} @ M W C N T$, which are also decorated with $\mathrm{Fe}_{3} \mathrm{O}_{4}$ NPs. We note that $\mathrm{Fe}_{3} \mathrm{O}_{4} @$ MWCNTs (retained) has MWCNTs decorated with $\mathrm{Fe}_{3} \mathrm{O}_{4}$ nanoparticles with an average diameter of $15.1 \pm 2.4 \mathrm{~nm}$, as determined using 

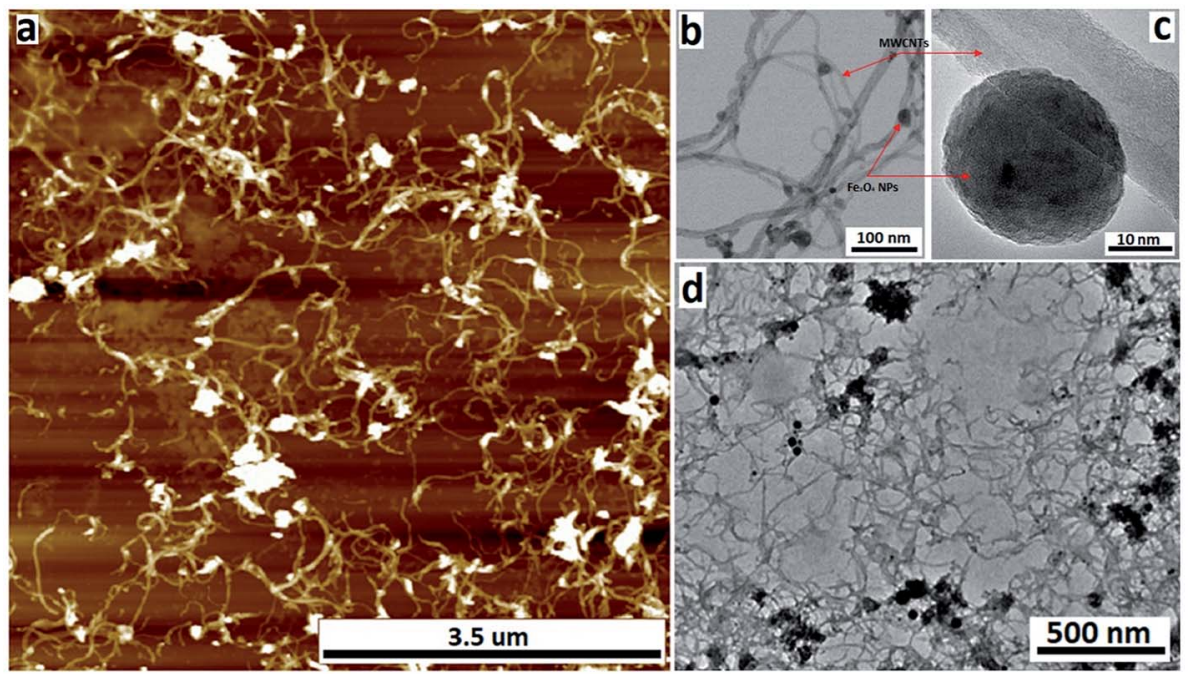

Fig. 2 (a) AFM image, (b) STEM image, (c) HRTEM image and (d) TEM of $\mathrm{Fe}_{3} \mathrm{O}_{4}$ (aMWCNT (retained), formed in the VFD (optimised parameters) operating at $8.5 \mathrm{k} \mathrm{rpm}$ rotational speed, under continuous flow, with the concentration of the as received $\mathrm{MWCNTs}$ at $0.08 \mathrm{mg} \mathrm{mL}^{-1}$ (DMF), tilt

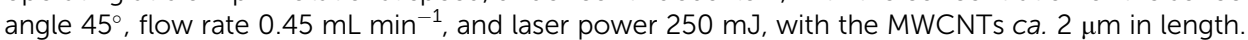

HRTEM, Fig. 2c, whereas they are smaller in diameter, $10 \pm$ $1.2 \mathrm{~nm}$, for the material exiting the VFD tube under flow, Fig. 3c.

High-resolution STEM was used to gain further insight into the nature of the $\mathrm{Fe}_{3} \mathrm{O}_{4} @ M W C N T$ nanocomposite. Fig. 4a displays $\mathrm{BF}$ and HAADF-STEM images of collected $\mathrm{Fe}_{3} \mathrm{O}_{4}$ @MWCNT along with the elemental mapping. Interestingly, while most $\mathrm{Fe}_{3} \mathrm{O}_{4}$ NPs decorate the surface of the MWCNTs, Fig. 3a and $b$, there are some that are encapsulated inside the MWCNTs, Fig. 4a, as highlighted by elemental mapping of $\mathrm{Fe}$ and $\mathrm{O}$. BF and HAADF-STEM images, and the corresponding elemental mapping, for the collected material are shown in Fig. 4b, with the mapping consistent with coating of MWCNTs with $\mathrm{Fe}_{3} \mathrm{O}_{4}$ NPs. BF and HAADF, and STEM images, Fig. 4a and $\mathrm{b}$ also establish that the size of $\mathrm{Fe}_{3} \mathrm{O}_{4}$ nanoparticles for the
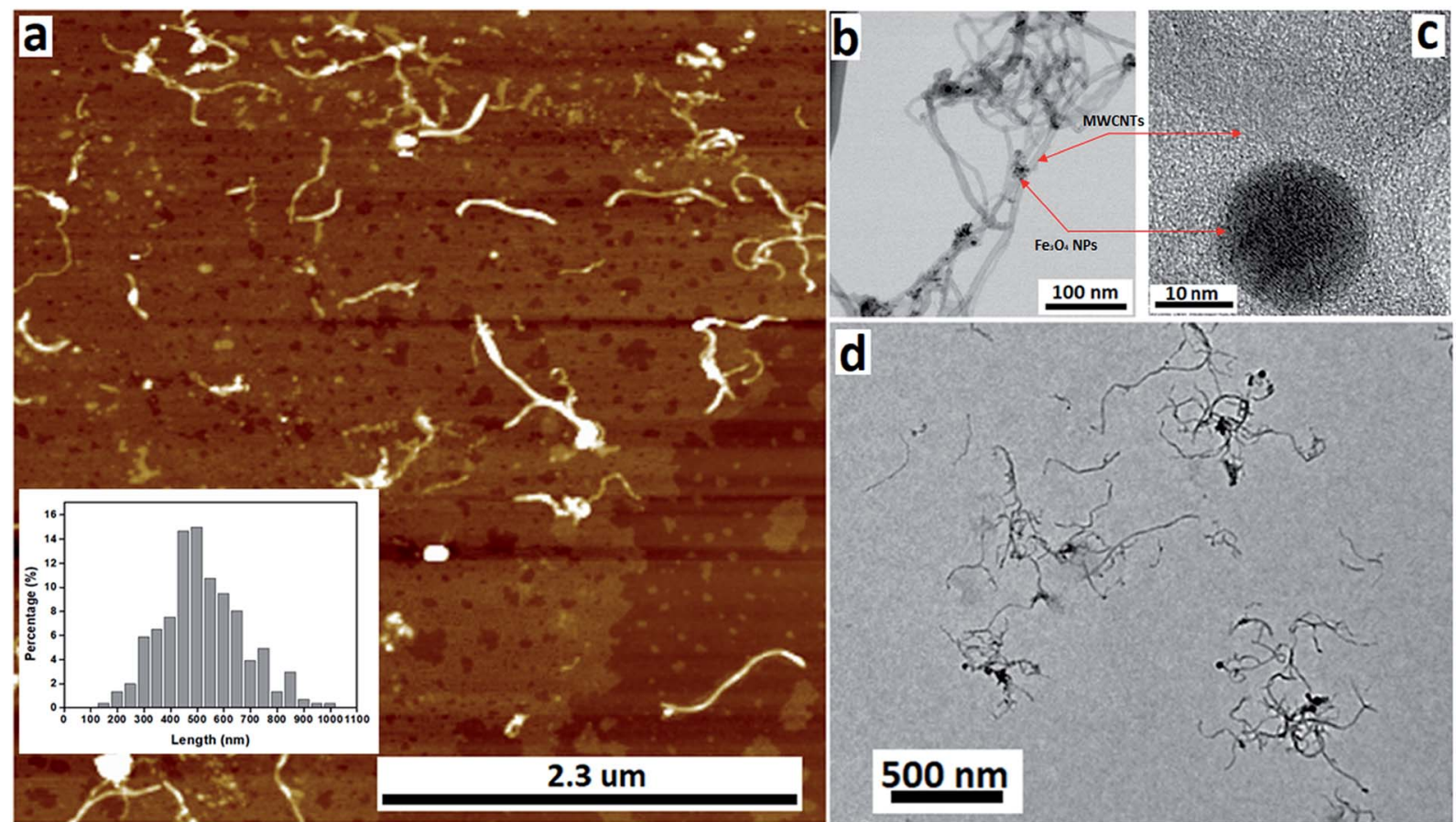

Fig. 3 (a) AFM image, (b) STEM image, (c) HRTEM image and (d) TEM image of $\mathrm{Fe}_{3} \mathrm{O}_{4}$ @MWCNT exiting the tube under continuous flow (collected), processed in the VFD (optimised parameters) operating at $8.5 \mathrm{k} \mathrm{rpm}$ rotational speed, with the concentration of the as received MWCNTs at $0.08 \mathrm{mg} \mathrm{mL}^{-1}$ (DMF), tilt angle $45^{\circ}$, flow rate $0.45 \mathrm{~mL} \mathrm{~min}^{-1}$, and laser power $250 \mathrm{~mJ}$. The inset in (a) is the length distribution of the carbon nanotubes in $\mathrm{Fe}_{3} \mathrm{O}_{4}$ (MMWCNTs (collected). 

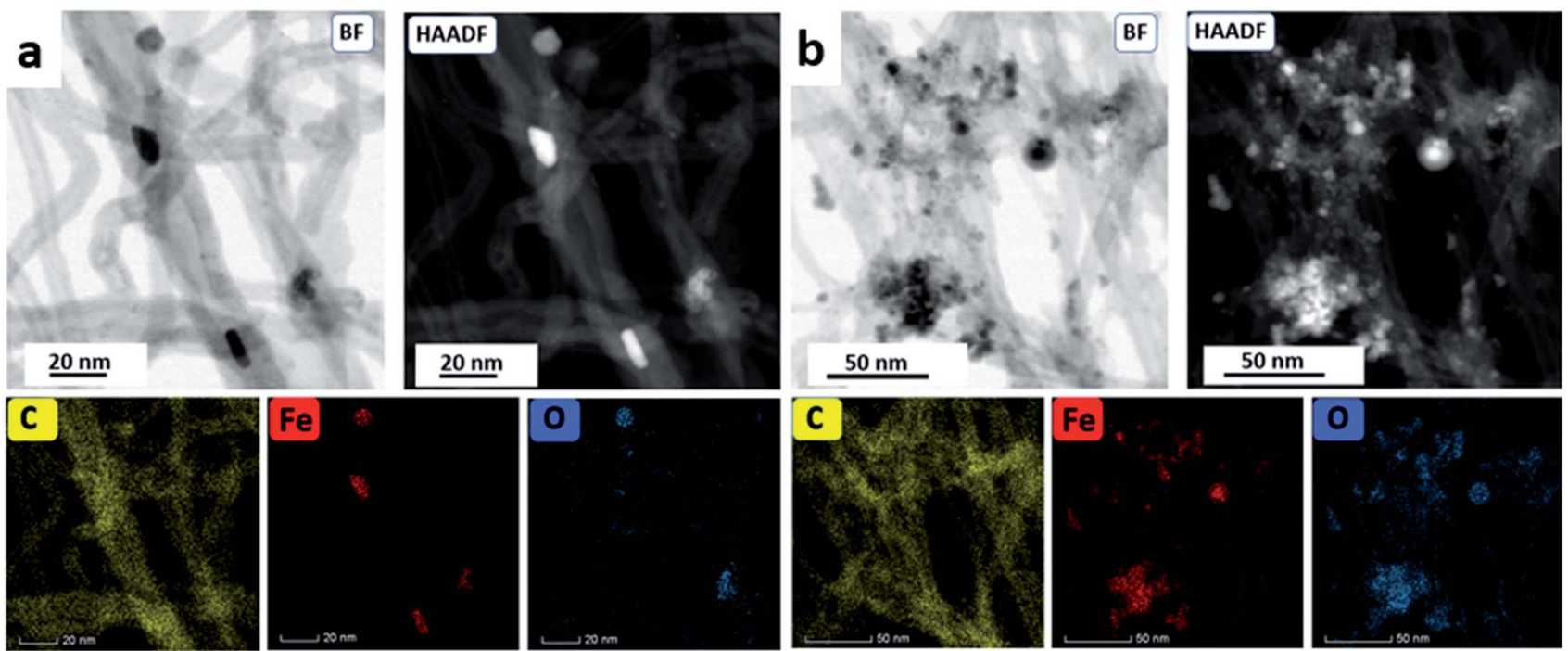

Fig. 4 (a) BF and HAADF-STEM images of $\mathrm{Fe}_{3} \mathrm{O}_{4}$ (aMWCNT (collected) with the corresponding STEM element mapping. (b) BF and HAADF-STEM image of $\mathrm{Fe}_{3} \mathrm{O}_{4} @ \mathrm{OMWCNT}$ (retained) with the corresponding STEM element mapping.

collected material are smaller than those of the retained material. In addition, VFD processing in the absence of MWCNTs, generated $\mathrm{Fe}_{3} \mathrm{O}_{4}$ nanoparticles which were also smaller for the collected material, average diameter $c a .10 \mathrm{~nm}$, compared to the material retained in the VFD, average diameter ca. 15, as determined using AFM (ESI Fig. S8 $\dagger$ ). This is in good agreement with HRTEM results for the NPs formed in the presence of MWCNTs, Fig. 2c and 3c. The results suggest that the larger particles, which have higher mass, determine whether the MWCNTs are decorated and sliced and free to leave the tube, or decorated without slicing and retained in the tube, i.e. if the build-up of NPs on the surface of MWCNTs is too fast relative to slicing the MWCNTs, then they will be retained in the quartz tube in the VFD. Additional STEM images are provided in the ESI, Fig. S3 and S4. $\dagger$

The X-ray diffraction (XRD) patterns of MWCNTs before processing (as received), $\mathrm{Fe}_{3} \mathrm{O}_{4} @ M W C N T$ (collected and retained) samples are shown in Fig. 5a. MWCNTs (as received) have diffraction peaks at $29.7^{\circ}$ and $51.2^{\circ}$, which are assigned to the (002) and (110) planes of MWCNTs (ESI Fig. S6 $†$ ), ${ }^{15,27}$ whereas for $\mathrm{Fe}_{3} \mathrm{O}_{4}$ nanoparticles only, there are seven characteristic peaks $\left(21.5^{\circ}, 37.3^{\circ}, 44.6^{\circ}, 54.9^{\circ}, 62^{\circ}, 69.1^{\circ}\right.$, and $\left.74.1^{\circ}\right)$ which correspond to the (111), (220), (311), (400), (422), (511), and (440) reflections of magnetite $\left(\mathrm{Fe}_{3} \mathrm{O}_{4}\right.$ ) (ESI Fig. S6 $\dagger$ ). ${ }^{26,27,31,38}$ XRD pattern for the nanocomposite material is shown in Fig. 5a, establishing the formation of magnetic NPs, with all of the peaks corresponding to magnetite and MWCNTs, consistent with the formation of $\mathrm{Fe}_{3} \mathrm{O}_{4} @$ MWCNT.

Thermogravimetric analysis (TGA) was carried out under air, for MWCNTs (as received), (ESI Fig. S7 $\dagger$ ), and both $\mathrm{Fe}_{3} \mathrm{O}_{4}$ @MWCNT nanocomposite materials (retained and collected), Fig. 5b. For as-received MWCNTs the material is stable when the temperature is $<550{ }^{\circ} \mathrm{C}$, with then a significant weight loss $>600^{\circ} \mathrm{C}$ corresponding to the decomposition of MWCNTs ${ }^{56}$ The weight loss of retained $\mathrm{Fe}_{3} \mathrm{O}_{4} @ M W C N T$ nanocomposite was about $29.6 \mathrm{wt} \%$ between temperature $350-650{ }^{\circ} \mathrm{C}$, whereas, the collected nanocomposite shows greater weight loss for increasing temperatures. Here there are two regions of weight
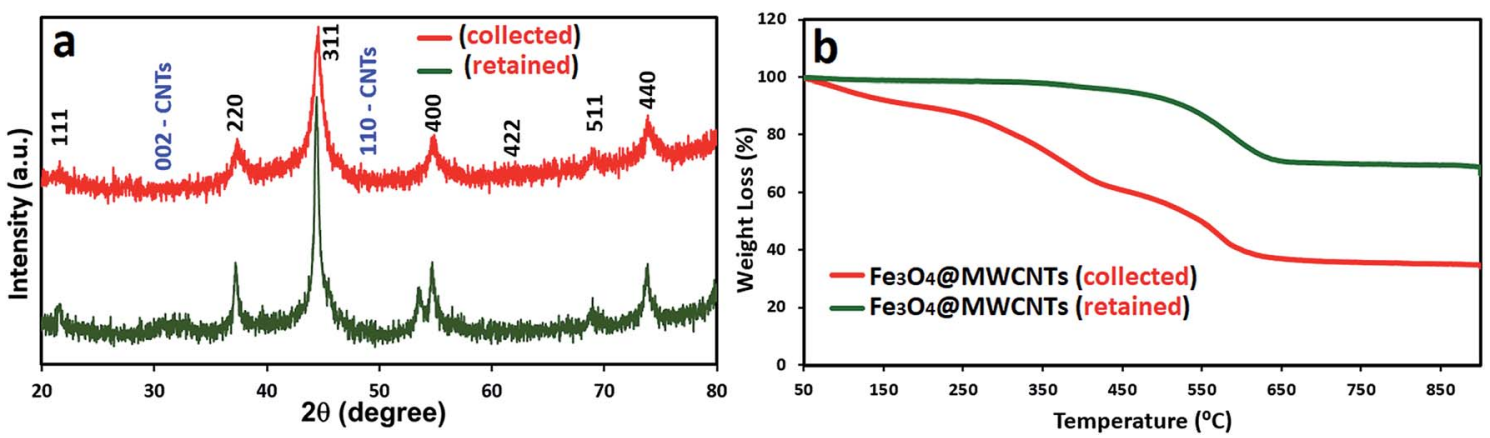

Fig. 5 (a) XRD patterns and (b) TGA curves for $\mathrm{Fe}_{3} \mathrm{O}_{4}$ (aMWCNT exiting (red) and retained (green) in the quartz tube, processed in the VFD (optimised parameters) operating at $8.5 \mathrm{k} \mathrm{rpm}$ rotational speed, with the concentration of the as received $\mathrm{MWCNTs}$ at $0.08 \mathrm{mg} \mathrm{mL}{ }^{-1}$ (DMF), tilt angle $45^{\circ}$, flow rate $0.45 \mathrm{~mL} \mathrm{~min}^{-1}$, and laser power $250 \mathrm{~mJ}$. 
loss, 40 and $25 \mathrm{wt} \%$ between $50-400{ }^{\circ} \mathrm{C}$ and $400-650{ }^{\circ} \mathrm{C}$, respectively. The differences in the weight loss between two nanocomposite material (retained and collected) is ascribed to the uptake of DMF in solution when the MWCNTs are sliced. If the material retained in the VFD quartz tube is unsliced or has very little slicing, the end caps of the MWCNTs will limit the amount of solvent that can be taken up inside the nanotubes. $^{57,58}$ Specific surface area from BET for MWCNTs (as received), $\mathrm{Fe}_{3} \mathrm{O}_{4} @ M W C N T$ (collected) and $\mathrm{Fe}_{3} \mathrm{O}_{4} @ M W C N T$ (retained) are $127.0396 \mathrm{~m}^{2} \mathrm{~g}^{-1}, 83.8937 \mathrm{~m}^{2} \mathrm{~g}^{-1}$ and $55.1279 \mathrm{~m}^{2}$ $\mathrm{g}^{-1}$, respectively, Fig. S9. $\uparrow$ The lower surface area for $\mathrm{Fe}_{3} \mathrm{O}_{4}$ @MWCNT (collected) and $\mathrm{Fe}_{3} \mathrm{O}_{4} @ M W C N T$ (retained) compared to as received MWCNTs presumably relates to the build up of magnetite material, lowering the relative surface area. The higher surface area for the material exiting the tube relates to the now availability of the internal surface of the sliced MWCNTs. ${ }^{59}$

X-ray photoelectron spectroscopy (XPS) was used to investigate the elemental composition and chemical state of $\mathrm{Fe}_{3}$ $\mathrm{O}_{4} @$ MWCNT, with the results shown in Fig. 6. The XPS C 1s spectrum for $\mathrm{Fe}_{3} \mathrm{O}_{4} @ M W C N T$ (retained and collected) is shown in Fig. 6a and c respectively, with three peaks, at $285.1 \mathrm{eV}$, $286.8 \mathrm{eV}$ and $289.1 \mathrm{eV}$, corresponding to $\mathrm{C}-\mathrm{C}, \mathrm{C}-\mathrm{O}$ and $\mathrm{C}=\mathrm{O}$ groups, ${ }^{\mathbf{6 0}, 61}$ respectively. Fig. $6 \mathrm{~b}$ and $\mathrm{d}$ show the XPS Fe $2 \mathrm{p}$ spectra for retained and collected material, with two peaks at 711.5 and $724.7 \mathrm{eV}$, which are assigned to the $\mathrm{Fe} 2 \mathrm{p}_{3 / 2}$ and $\mathrm{Fe}$ $2 \mathrm{p}_{1 / 2}$ binding energies, ${ }^{37,62}$ respectively.

The magnetic behaviour of $\mathrm{Fe}_{3} \mathrm{O}_{4} @ M W C N T$ composites was investigated by placing a suspension of the composite materials $\mathrm{Fe}_{3} \mathrm{O}_{4} @ M W C N T s$ in water, separately retained and collected, close to an external magnet, Fig. $6 e$ and $\mathrm{f}$. Both show a dramatic response with accumulation of the material towards the magnet. In addition, their response to magnetic fields between $\pm 2.5 \mathrm{~T}$ where studied, with the results presented in Fig. $6 \mathrm{~g}$. Both composite materials (retained and collected) have similar shaped hysteresis loops. The saturation magnetization $\left(M_{\mathrm{s}}\right)$ of $\mathrm{Fe}_{3} \mathrm{O}_{4}$ @MWCNT (retained) is $19.3 \mathrm{~A} \mathrm{~m}^{2} \mathrm{~kg}^{-1}$ establishing high magnetism and exhibiting typical ferromagnetic behaviour, being consistent with the results in literature values for superparamagnetic nanoparticles of magnetite. ${ }^{57}$ In contrast, $\mathrm{Fe}_{3}$ $\mathrm{O}_{4} @$ MWCNT collected under continuous flow has weak magnetic properties, with $M_{\mathrm{s}}$ of $6.2 \mathrm{~A} \mathrm{~m}^{2} \mathrm{~kg}^{-1}$. This is consistent with smaller sized magnetite particles decorating the MWCNTs (collected). ${ }^{63-65}$

\subsection{Electrochemical response}

Finally, in order to demonstrate a practical application of $\mathrm{Fe}_{3}$ $\mathrm{O}_{4} @$ @WCNT composites, they were used as electrodes for assembly of a supercapacitor with the performance presented for selected results in Fig. 7. The electrochemical behaviour of MWCNTs (as received), and $\mathrm{Fe}_{3} \mathrm{O}_{4} @$ MWCNTs (retained and collected) were tested using cyclic voltammetry (CV) and galvanostatic charge/discharge (CD) in a two-electrode cell configuration with $1.0 \mathrm{M} \mathrm{Na}_{2} \mathrm{SO}_{4}$ as an electrolyte by a CHI 760E electrochemical workstation. Fig. 7a shows the CV curves of electrodes of these materials at a scan rate of $60 \mathrm{mV} \mathrm{s}^{-1}$. MWCNTs (as received) displayed CV curves with typical rectangular shape due to the clear EDLC behaviour. After adding $\mathrm{Fe}_{3} \mathrm{O}_{4}$ as pseudocapacitive material, $\mathrm{Fe}_{3} \mathrm{O}_{4} @ M W C N T$ (retained) and $\mathrm{Fe}_{3} \mathrm{O}_{4} @$ MWCNTs (collected) had deformed CV curves with larger integrated area than MWCNTs (as received), thereby confirming the role of $\mathrm{Fe}_{3} \mathrm{O}_{4}$ in the composites for improving
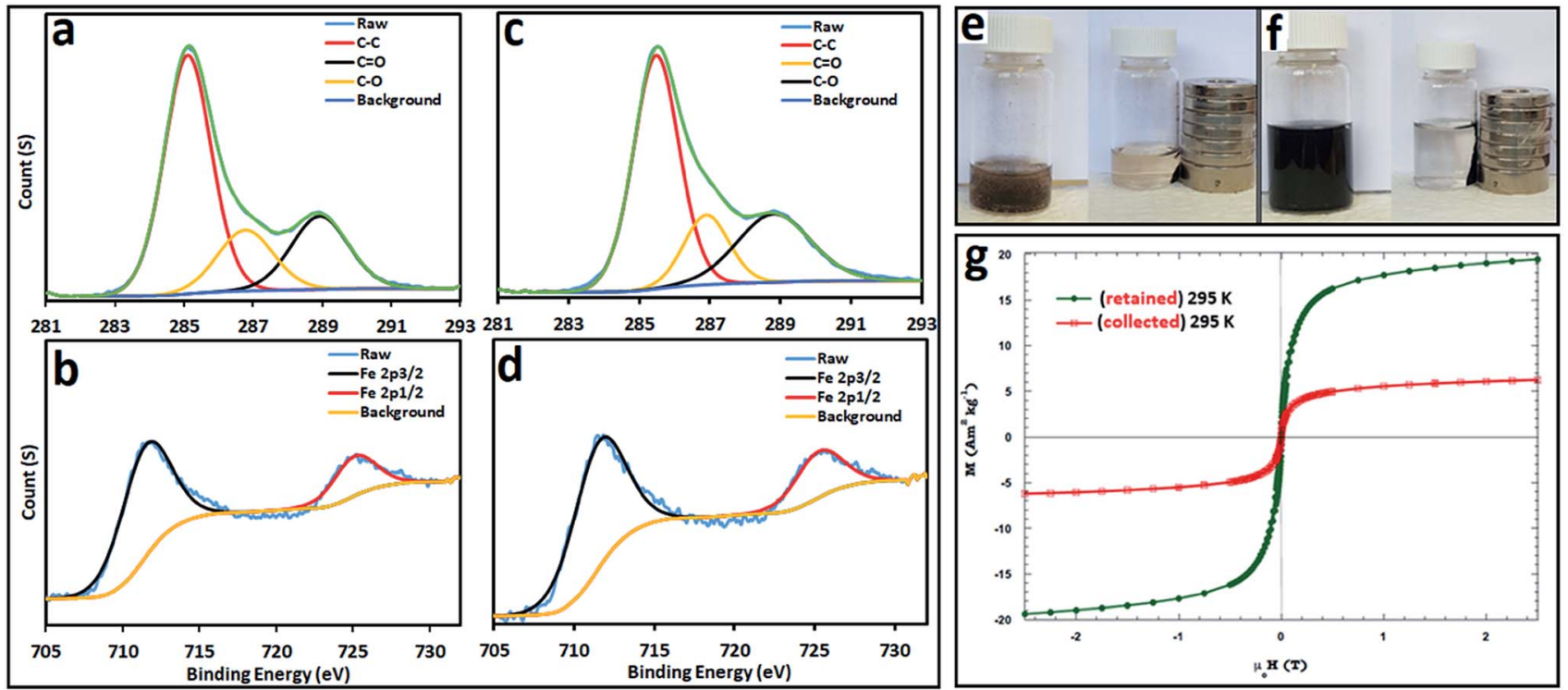

Fig. 6 High-resolution XPS spectra for $\mathrm{Fe}_{3} \mathrm{O}_{4}$ (aMWCNT: (a) C 1s and (b) Fe 2p (collected), and (c) C 1s and (b) Fe 2p (retained). (e and f) Photographs of $\mathrm{Fe}_{3} \mathrm{O}_{4} \mathrm{aMWCNT}$, collected and retained when placed next to a magnet, and $(\mathrm{g})$ magnetic hysteresis loops for $\mathrm{Fe}_{3} \mathrm{O}_{4} @ \mathrm{MWWCNTs}$ (collected out of the tube, red line, and retained in the tube, green line), processed in the VFD (at optimised condition) operating at $8.5 \mathrm{k}$ rpm rotational speed, under continuous flow, with the concentration of the as received MWCNTs at $0.08 \mathrm{mg} \mathrm{mL}^{-1}$ (DMF), tilt angle $45^{\circ}$, flow rate 0.45 $\mathrm{mL} \mathrm{min}^{-1}$, and laser power $250 \mathrm{~mJ}$. 

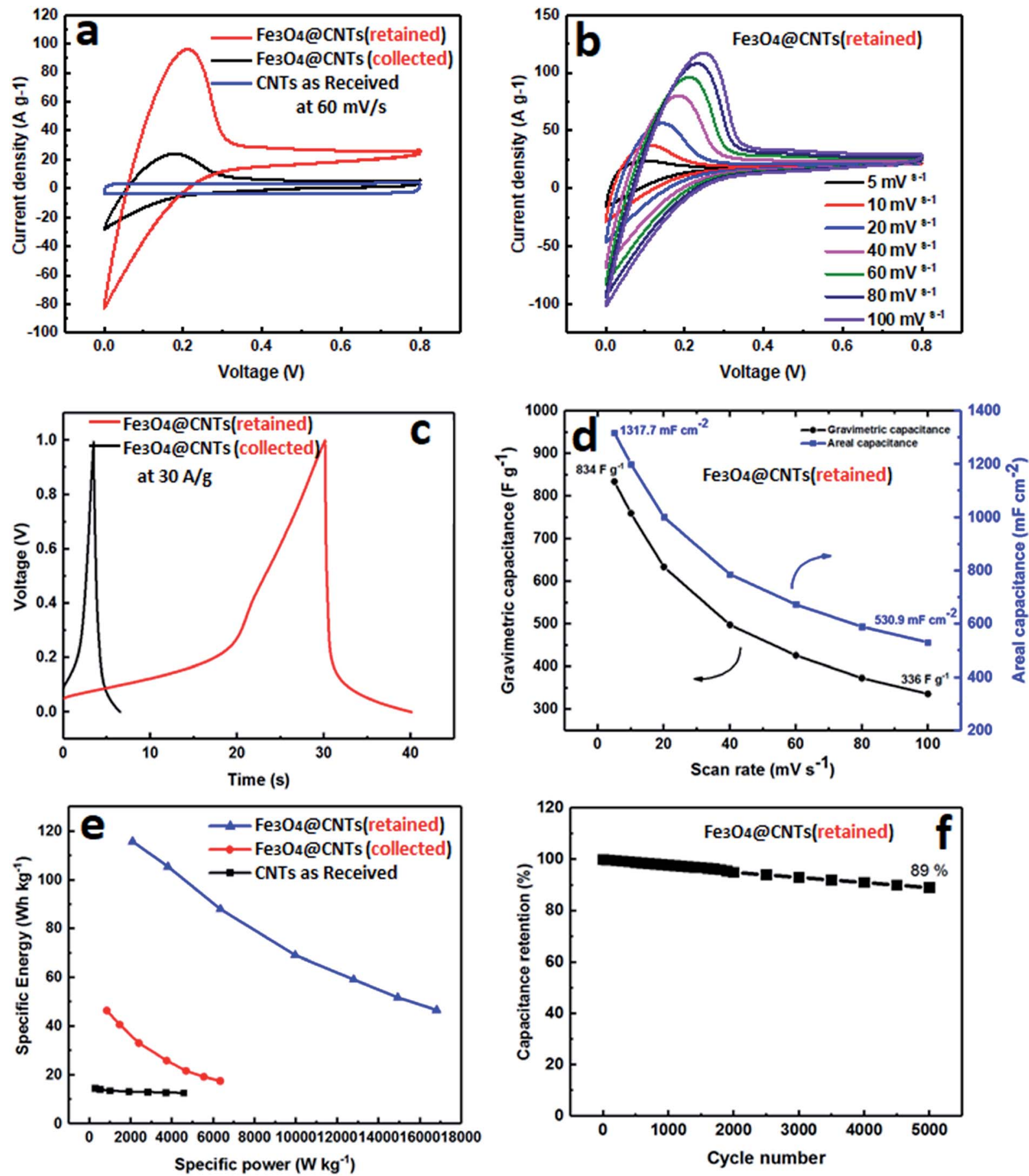

Fig. 7 (a) Cyclic Voltammogram (CV) curves of MWCNTs (as received), $\mathrm{Fe}_{3} \mathrm{O}_{4}$ (aMWCNT (retained) and Fe $\mathrm{O}_{4}$ @MWCNTs (collected) at 60 mV s ${ }^{-1}$, (b) CV curves of $\mathrm{Fe}_{3} \mathrm{O}_{4} @ \mathrm{aMWCNT}$ (collected) at different scan rates from 5 to $100 \mathrm{mV} \mathrm{s}{ }^{-1}$ and (c) charge-discharge curves of Fe $\mathrm{O}_{4} @ \mathrm{MMWCNT}$ (retained and collected), (d) gravimetric capacitance and areal capacitance values versus scanning rate calculated from the CV curves of the $\mathrm{Fe}_{3} \mathrm{O}_{4} \mathrm{QMWCNT}$ (retained). (e) Specific energy vs. specific power of $\mathrm{Fe}_{3} \mathrm{O}_{4}\left(\mathrm{aMWCNT}\right.$ (retained). (f) Cycle performance of the Fe $\mathrm{O}_{4} @ \mathrm{aMWCNT}$ (retained).

the electrochemical performance. However, the $\mathrm{Fe}_{3} \mathrm{O}_{4} @$ @MWCNT (retained) electrode exhibited much higher current densities than those of the collected $\mathrm{Fe}_{3} \mathrm{O}_{4}$ @MWCNT electrode, and the enclosed area of $\mathrm{Fe}_{3} \mathrm{O}_{4} @$ @WCNTs (retained) is also much larger than that of $\mathrm{Fe}_{3} \mathrm{O}_{4} @$ @WCNTs (collected), showing that the capacitance is significantly increased after adding more
$\mathrm{Fe}_{3} \mathrm{O}_{4}$ decoration owing to the significant synergistic effect between the $\mathrm{Fe}_{3} \mathrm{O}_{4}$ and MWCNTs in the composite. The $\mathrm{CV}$ curves of $\mathrm{Fe}_{3} \mathrm{O}_{4} @$ MWCNTs (retained) at different scan rates, ranging from 5 to $100 \mathrm{mV} \mathrm{s}^{-1}$, are shown in Fig. $7 \mathrm{~b}$, displaying typical pseudocapacitive behaviour at different scan rates, indicating good charge propagation at the electrode surface. 
The current response in the CV curves increases proportionally with increasing scan rates, suggesting that the rates of electronic and ionic transport are not limiting at scan rates as high as $100 \mathrm{mV} \mathrm{s}^{-1}$.

The charge/discharge (CD) curves of both $\mathrm{Fe}_{3} \mathrm{O}_{4} @ M W C N T$ (retained and collected) are shown in Fig. 7c, confirming the same behaviour as displayed in CV measurements, and that $\mathrm{Fe}_{3} \mathrm{O}_{4} @ M W C N T$ (retained) has a longer charge and discharge time than $\mathrm{Fe}_{3} \mathrm{O}_{4}$ @MWCNTs (collected) with noticeable deviation from linearity. Fig. 7d shows the areal and gravimetric $\left(C_{\mathrm{wt}}\right)$ capacitances of the $\mathrm{Fe}_{3} \mathrm{O}_{4}$ @MWCNTs (retained) at different scan rates, ranging from 10 to $100 \mathrm{mV} \mathrm{s}^{-1}$, which were calculated from the CV curves of eqn (S1) and (S2) in the ESI. $\dagger$ The $\mathrm{Fe}_{3} \mathrm{O}_{4} @ M W C N T s$ (retained) electrode delivers gravimetric of $834 \mathrm{~F} \mathrm{~g}^{-1}$ and areal capacitance of $1317.7 \mathrm{mF} \mathrm{cm}^{-2}$ at a scan rate of $10 \mathrm{mV} \mathrm{s}^{-1}$. The exceptionally high value of the areal capacitance of the $\mathrm{Fe}_{3} \mathrm{O}_{4} @$ @WWNTs (retained) electrode $(1317.7 \mathrm{mF}$ $\mathrm{cm}^{-2}$ ), highlights potential advantages of these composite materials and the method which was used to prepare them. The areal capacitance achieved in the present study is considerably higher or comparable than the recently reported values when using composite carbon materials for supercapacitor, such as (GF-CNT@Fe $\left.{ }_{2} \mathrm{O}_{3}\right)\left(659.5 \mathrm{mF} \mathrm{cm}{ }^{-2}\right.$ at $\left.5 \mathrm{~mA} \mathrm{~cm}^{-2}\right),{ }^{41}(\mathrm{Ni} / \mathrm{GF} /$ $\left.\mathrm{Fe}_{2} \mathrm{O}_{3}\right)\left(572 \mathrm{mF} \mathrm{cm}{ }^{-2}\right.$ at $\left.1 \mathrm{~mA} \mathrm{~cm}^{-2}\right){ }^{66}$ (rGO-PEDOT/PSS films) (448 $\mathrm{mF} \mathrm{cm}^{-2}$ at $\left.10 \mathrm{mV} \mathrm{s}^{-1}\right),{ }^{67}\left(\mathrm{H}_{2} \mathrm{SO}_{4}\right.$-PVA this electrolyte, find materials) (402 $\left.\mathrm{mF} \mathrm{cm}{ }^{-2}\right){ }^{68}(\mathrm{FeOOH}-\mathrm{MWCNT})\left(0.58 \mathrm{~F} \mathrm{~cm}^{-2}\right.$ at $\left.100 \mathrm{mV} \mathrm{s}^{-1}\right){ }^{69}\left(\mathrm{MN}_{3} \mathrm{O}_{4}-\mathrm{MWCNTs}\right)\left(2.8 \mathrm{~F} \mathrm{~cm}^{-2}\right.$ at $\left.2 \mathrm{mV} \mathrm{s}^{-1}\right){ }^{70}$ (CNT hydrogel film with PANI) $\left(680 \mathrm{mF} \mathrm{cm}^{-2}\right.$ at $\left.1 \mathrm{~mA} \mathrm{~cm}^{-2}\right){ }^{71}$ and $\left(\mathrm{V}_{2} \mathrm{O}_{3}-\mathrm{MWCNT}\right)\left(4.4 \mathrm{~F} \mathrm{~cm}^{-2}\right.$ at $\left.2 \mathrm{mV} \mathrm{s}^{-1}\right) .{ }^{72} \mathrm{Fig}$. 7e features the Ragone plot of the calculated specific energy and specific power based on the total mass of electroactive materials in the two electrodes. The $\mathrm{Fe}_{3} \mathrm{O}_{4} @ M W C N T$ (retained) electrode delivers a significant high specific energy of $115.84 \mathrm{~W} \mathrm{~h} \mathrm{~kg}^{-1}$ at specific power of $2085 \mathrm{~W} \mathrm{~kg}^{-1}$. However, it can only provide a specific energy of $46.68 \mathrm{~W} \mathrm{~h} \mathrm{~kg}{ }^{-1}$ at a specific power of $16803.33 \mathrm{~W} \mathrm{~kg}^{-1}$. More interestingly, the cyclic durability of the $\mathrm{Fe}_{3} \mathrm{O}_{4} @ M W C N T s$ (retained), shown in Fig. 7f, establishes excellent cycling ability. The $\mathrm{Fe}_{3} \mathrm{O}_{4} @$ @WCNT (retained) electrode was tested for 5000 charge-discharge cycles at a current density of $30 \mathrm{~A} \mathrm{~g}^{-1}$, retaining $89 \%$ of the initial capacitance, and thus establishing good cycling performance.

\section{Conclusion}

We report a simple and effective method for decorating MWCNTs with superparamagnetic magnetite $\left(\mathrm{Fe}_{3} \mathrm{O}_{4}\right)$ NPs using the VFD thin film microfluidic platform. The main advantages of the processing include that it is a focused three in one process, involving slicing the MWCNTs, generating the magnetite nanoparticles in situ, and the decoration of the MWCNTs. Both the slicing and the generation of the magnetite nanoparticles features the use of a pulsed laser operating at $1064 \mathrm{~nm}$. This dual field effect application of the VFD adds to the versatility of the device, extending its field effect capabilities, with others including plasma processing and continuous light sources. ${ }^{73,74}$
The generation of $\mathrm{Fe}_{3} \mathrm{O}_{4} @ M W C N T$ directly from pristine MWCNTs avoids the use of harsh chemicals while dramatically reducing the processing time, all of which are important in developing any applications. To this end, we have demonstrated the utility of the composite material retained in the VFD tube, in a high performing supercapacitor. The nanocomposite material (retained), resulted in a high areal capacitance $(1317.7 \mathrm{mF}$ $\mathrm{cm}^{-2}$ ) which is much larger than reported for other $\mathrm{Fe}_{3} \mathrm{O}_{4}$ @CNTs electrodes.

\section{Author contributions}

All authors have given approval to the final version of the manuscript.

\section{Conflicts of interest}

The authors declare no competing financial interest.

\section{Acknowledgements}

T. M. D. A. would like to thank Taibah University (Ministry of Education, Saudi Arabia) for funding his scholarship. The authors also thank the Australian Research Council, The Government of South Australia, Adelaide Microscopy and AMMRF for support of this work.

\section{References}

1 H. Jiang, P. S. Lee and C. Li, Energy Environ. Sci., 2013, 6, 4153.

2 F. Ran, X. Yang and L. Shao, Advanced Composites and Hybrid Materials., 2018, 1, 32-55.

3 Z. Yang, J. Ren, Z. Zhang, X. Chen, G. Guan, L. Qiu, Y. Zhang and H. Peng, Chem. Rev., 2015, 115, 5159-5223.

4 L. L. Zhang and X. S. Zhao, Chem. Soc. Rev., 2009, 38, 25202531.

5 L. L. Zhang, R. Zhou and X. S. Zhao, J. Mater. Chem., 2010, 20, 5983-5992.

6 Y. Huang, J. Liang and Y. Chen, Small, 2012, 8, 1805-1834.

7 Q. Liao, N. Li, S. Jin, G. Yang and C. Wang, ACS Nano, 2015, 9, 5310-5317.

8 L. Yuan, X.-H. Lu, X. Xiao, T. Zhai, J. Dai, F. Zhang, B. Hu, X. Wang, L. Gong, J. Chen, C. Hu, Y. Tong, J. Zhou and Z. Wang, ACS Nano, 2011, 6, 656-661.

9 Z. Chen, V. Augustyn, J. Wen, Y. Zhang, M. Shen, B. Dunn and Y. Lu, Adv. Mater., 2011, 23, 791-795.

10 P.-C. Chen, G. Shen, Y. Shi, H. Chen and C. Zhou, ACS Nano, 2010, 4, 4403-4411.

11 Y. Zhao, W. Ran, J. He, Y. Huang, Z. Liu, W. Liu, Y. Tang, L. Zhang, D. Gao and F. Gao, Small, 2015, 11, 1310-1319.

12 S. G. Mohamed, C.-J. Chen, C. K. Chen, S.-F. Hu and R.-S. Liu, ACS Appl. Mater. Interfaces, 2014, 6, 22701-22708.

13 J. Chang, M. Jin, F. Yao, T. H. Kim, V. T. Le, H. Yue, F. Gunes, B. Li, A. Ghosh, S. Xie and Y. H. Lee, Adv. Funct. Mater., 2013, 23, 5074-5083. 
14 C. X. Guo and C. M. Li, Energy Environ. Sci., 2011, 4, 45044507.

15 A. L. M. Reddy and S. Ramaprabhu, J. Phys. Chem. C, 2007, 111, 7727-7734.

16 M. Zhi, C. Xiang, J. Li, M. Li and N. Wu, Nanoscale, 2013, 5, 72-88.

17 J. Tucek, K. C. Kemp, K. S. Kim and R. Zboril, ACS Nano, 2014, 8, 7571-7612.

18 H.-S. Kim, H. Lee, K.-S. Han, J.-H. Kim, M.-S. Song, M.-S. Park, J.-Y. Lee, J.-K. Kang and J.-K. Kang, J. Phys. Chem. B, 2005, 109, 8983-8986.

19 X. J. Liu, I. Marangon, G. Melinte, C. Wilhelm, C. MenardMoyon, B. P. Pichon, O. Ersen, K. Aubertin, W. Baaziz, C. Pham-Huu, S. Begin-Colin, A. Bianco, F. Gazeau and D. Begin, ACS Nano, 2014, 8, 11290-11304.

20 A. Star, V. Joshi, S. Skarupo, D. Thomas and J.-C. P. Gabriel, J. Phys. Chem. B, 2006, 110, 21014-21020.

21 G.-W. Yang, G.-Y. Gao, C. Wang, C.-L. Xu and H.-L. Li, Carbon, 2008, 46, 747-752.

22 Q. Liu, W. Ren, Z.-G. Chen, B. Liu, B. Yu, F. Li, H. Cong and H.-M. Cheng, Carbon, 2008, 46, 1417-1423.

23 S. Y. Lee, W. C. Choi, C. Jeon, C.-Y. Park, J. H. Yang and M. H. Kwon, Appl. Phys. Lett., 2008, 93, 103101.

24 M. Liebau, E. Unger, G. Duesberg, A. Graham, R. Seidel, F. Kreupl and W. Hoenlein, Appl. Phys. A, 2003, 77, 731-734.

25 P. C. Ma, B. Z. Tang and J.-K. Kim, Carbon, 2008, 46, 14971505.

26 J. Deng, X. Wen and Q. Wang, Mater. Res. Bull., 2012, 47, 3369-3376.

27 D. Guan, Z. Gao, W. Yang, J. Wang, Y. Yuan, B. Wang, M. Zhang and L. Liu, Mater. Sci. Eng., B, 2013, 178, 736-743.

28 Y. Chen and H. Gu, Mater. Lett., 2012, 67, 49-51.

29 S. J. Henley, S. Mollah, C. E. Giusca and S. R. P. Silva, J. Appl. Phys., 2009, 106, 064309.

30 Z. Sun, Z. Li, C. Huang, Y. Zhao, H. Zhang, R. Tao and Z. Liu, Carbon, 2011, 49, 4376-4384.

31 H. Zhou, C. Zhang, H. Li and Z. Du, J. Polym. Sci., Part A: Polym. Chem., 2010, 48, 4697-4703.

32 M. Morales, O. Bomati-Miguel, R. P. De Alejo, J. RuizCabello, S. Veintemillas-Verdaguer and K. O'Grady, J. Magn. Magn. Mater., 2003, 266, 102-109.

33 J. C. Tristao, A. A. Oliveira, J. D. Ardisson, A. Dias and R. M. Lago, Mater. Res. Bull., 2011, 46, 748-754.

34 J. Freedman, D. Mattia, G. Korneva, Y. Gogotsi, G. Friedman and A. K. Fontecchio, Appl. Phys. Lett., 2007, 90, 103108.

35 R. Singhal, Z. Orynbayeva, R. V. K. Sundaram, J. J. Niu, S. Bhattacharyya, E. A. Vitol, M. G. Schrlau, E. S. Papazoglou, G. Friedman and Y. Gogotsi, Nat. Nanotechnol., 2011, 6, 57.

36 B. Šljukić, C. E. Banks and R. G. Compton, Nano Lett., 2006, 6, 1556-1558.

37 W. Kim, J. S. Lee and J. Jang, RSC Adv., 2018, 8, 31874-31880. 38 X. Luo, A. H. Al-Antaki, T. M. Alharbi, W. D. Hutchison, Y.-c. Zou, J. Zou, A. Sheehan, W. Zhang and C. L. Raston, ACS Omega, 2018, 3, 11172-11178.
39 A. H. M. Al-antaki, X. Luo, A. Duan, R. N. Lamb, E. Eroglu, W. Hutchison, Y.-C. Zou, J. Zou and C. L. Raston, RSC Adv., 2018, 8, 40829-40835.

40 K. Vimalanathan, J. R. Gascooke, I. Suarez-Martinez, N. A. Marks, H. Kumari, C. J. Garvey, J. L. Atwood, W. D. Lawrance and C. L. Raston, Sci. Rep., 2016, 6, 22865.

41 C. Guan, J. Liu, Y. Wang, L. Mao, Z. Fan, Z. Shen, H. Zhang and J. Wang, ACS Nano, 2015, 9, 5198-5207.

42 S. F. Chin, K. S. Iyer and C. L. Raston, Lab Chip, 2008, 8, 439442.

43 T. M. Alharbi, K. Vimalanathan, W. D. Lawrance and C. L. Raston, Carbon, 2018, 140, 428-432.

44 X. Chen, J. F. Dobson and C. L. Raston, Chem. Commun., 2012, 48, 3703-3705.

45 T. M. Alharbi, D. Harvey, I. K. Alsulami, N. Dehbari, X. Duan, R. N. Lamb, W. D. Lawrance and C. L. Raston, Carbon, 2018, 137, 419-424.

46 Y. A. Goh, X. Chen, F. M. Yasin, P. K. Eggers, R. A. Boulos, X. Wang, H. T. Chua and C. L. Raston, Chem. Commun., 2013, 49, 5171-5173.

47 F. M. Yasin, R. A. Boulos, B. Y. Hong, A. Cornejo, K. S. Iyer, L. Gao, H. T. Chua and C. L. Raston, Chem. Commun., 2012, 48, 10102-10104.

48 X. Luo, A. H. M. Al-Antaki, K. Vimalanathan, J. Moffatt, K. Zheng, Y.-C. Zou, J. Zou, X. Duan, R. Lamb and S. Wang, React. Chem. Eng., 2018, 3, 164-170.

49 K. Vimalanathan, R. G. Shrestha, Z. Zhang, J. Zou, T. Nakayama and C. L. Raston, Angew. Chem., Int. Ed., 2017, 56, 8398-8401.

50 L. Yasmin, X. Chen, K. A. Stubbs and C. L. Raston, Sci. Rep., 2013, 3, 2282.

51 T. Z. Yuan, C. F. G. Ormonde, S. T. Kudlacek, S. Kunche, J. N. Smith, W. A. Brown, K. M. Pugliese, T. J. Olsen, M. Iftikhar and C. L. Raston, ChemBioChem, 2015, 16, 393396.

52 J. Britton, L. M. Meneghini, C. L. Raston and G. A. Weiss, Angew. Chem., 2016, 128, 11559-11563.

53 J. Britton, C. L. Raston and G. A. Weiss, Chem. Commun., 2016, 52, 10159-10162.

54 J. Britton, K. A. Stubbs, G. A. Weiss and C. L. Raston, Chem.Eur. J., 2017, 23, 13270-13278.

55 K. Vimalanathan and C. L. Raston, Adv. Mater. Technol., 2017, 2, 1600298.

56 M. Muruganathan, H. Mizuta and R. Sundara, Nano Lett., 2018, 18, 5688-5696.

57 X. Jia, W. Li, X. Xu, W. Li, Q. Cai and X. Yang, ACS Appl. Mater. Interfaces, 2015, 7, 3170-3179.

58 M. Hao, M. Tang, W. Wang, M. Tian, L. Zhang and Y. Lu, Composites, Part B, 2016, 95, 395-403.

59 J. O. Marques Neto, C. R. Bellato, C. H. de Souza, R. C. d. Silva and P. A. Rocha, J. Braz. Chem. Soc., 2017, 28, 2301-2312.

60 H. Chen, Z. Zhang, X. Wang, J. Chen, C. Xu, Y. Liu, Z. Yu and X. Wang, ACS Appl. Nano Mater., 2018, 1, 2386-2396.

61 T. Okpalugo, P. Papakonstantinou, H. Murphy, J. McLaughlin and N. Brown, Carbon, 2005, 43, 153-161. 
62 L. Liu, J. Lang, P. Zhang, B. Hu and X. Yan, ACS Appl. Mater. Interfaces, 2016, 8, 9335-9344.

63 J. Wu and L. Kong, Appl. Phys. Lett., 2004, 84, 4956-4958.

64 C. Huiqun, Z. Meifang and L. Yaogang, J. Solid State Chem., 2006, 179, 1208-1213.

65 W. Zhao, L. Zhu, Y. Lu, L. Zhang, R. H. Schuster and W. Wang, Synth. Met., 2013, 169, 59-63.

66 K. Chi, Z. Zhang, Q. Lv, C. Xie, J. Xiao, F. Xiao and S. Wang, ACS Appl. Mater. Interfaces, 2017, 9, 6044-6053.

67 Y. Liu, B. Weng, J. M. Razal, Q. Xu, C. Zhao, Y. Hou, S. Seyedin, R. Jalili, G. G. Wallace and J. J. S. r. Chen, Sci. Rep., 2015, 5, 17045.

68 Y. Xu, Z. Lin, X. Huang, Y. Liu, Y. Huang and X. Duan, ACS Nano, 2013, 7, 4042-4049.
69 R. Chen, I. K. Puri and I. Zhitomirsky, Ceram. Int., 2018, 44, 18007-18015.

70 M. Ata, J. Milne and I. Zhitomirsky, J. Colloid Interface Sci., 2018, 512, 758-766.

71 S. Zeng, H. Chen, F. Cai, Y. Kang, M. Chen and Q. Li, J. Mater. Chem. A, 2015, 3, 23864-23870.

72 C. Wallar, R. Poon and I. Zhitomirsky, J. Electrochem. Soc., 2017, 164, A3620-A3627.

73 D. B. Jones, X. Chen, A. Sibley, J. S. Quinton, C. J. Shearer, C. T. Gibson and C. L. Raston, Chem. Commun., 2016, 52, 10755-10758.

74 L. A. Ho, C. L. Raston and K. A. Stubbs, Chem.-Eur. J., 2018, 24, 8869-8874. 